\title{
Clinical assessment of the arrest of myopia
}

\author{
T. STUART-BLACK KELLY*, C. CHATFIELD, and G. TUSTIN \\ Bath Eye Infirmary* and Bath University
}

During the last I 5 years, one of us (TS-BK) has tried various methods of treatment to arrest myopia. Most of the clinical data accumulated during this time were based on refraction and associated investigation. An assessment of the data is made in this paper in order to decide which methods of treatment seem to result in arrest. How these methods act is at present being investigated and will be reported later.

After considering several analytical approachessuch as, paired comparisons, and sequential analysis -we decided that the best way to present the data was by means of step graphs. These graphs show changes in refraction for a control group (Group I, who were untreated (Method I) except for the conventional trial lens refraction and spectacles), and also for the four groups treated by the four positive methods considered in this paper, namely: Method 2 Atropine I per cent three times a day for 7 days, then bifocals prescribed at the level of atropine refraction with no addition, and phenylephrine 5 per cent as drops at night. These were given for months or years until the myopia again began to increase, when Methods 4 and 5 were considered.

Method 3 Contact lenses without any previous treatment.

Method 4 Contact lenses after failure of treatment by Method 2.

Method 5 Atropine I per cent either once or twice daily for periods of several weeks or months, either initially to reduce the myopia as much as possible, or after failure of Method 4.

The evidence collected suggests that all four positive methods of treatment have a substantial effect in arresting myopia.

\section{THE STEP GRAPH}

Altogether I9 step graphs (A to $S$ ) were prepared, but Graphs B, D, E, F, G, I, K, M, and S have been omitted from this report, and the results

Address for reprints: T. Stuart-Black Kelly, FRCS, Linden, Weston Road, Bath BAI 2XU summarized in the Tables. It is important that the reader understands the step graphs. Taking graph $A$, for example, consider the row marked with an arrow. It shows what happened to a total of 13 eyes in Group I (that is, untreated) whose refraction at age ro years was -1.5 dioptres. After one year, one eye had stayed the same giving an observation ' $I$ ' in the column headed $I \cdot 5$. But in the remaining 12 eyes the myopia had increased during the year to the refraction indicated by the columns in which they appear. For example, in two eyes the myopia increased from -1.5 at the age of 10 to -2.75 at the age of II years.

Observations above the 'steps' relate to eyes which have become more myopic during the year. Observations below the 'steps' relate to eyes which have stayed the same or improved; these are arrests. In Graph A only 13 eyes out of 86 ( 15 per cent) have arrested (that is, are below the steps).

\section{THE REFRACTIONS}

The refractions in Graphs A to $P$ (Groups I, II, and III) were performed without cycloplegia. In Graphs $G$ to $M$, the refraction row 'before' was prior to the use of atropine, but the actual spectacle lens was then given at the atropine level not indicated in the graph.

In $Q$, the contact lens was also fitted at the atropine level but was indicated in the 'before' row because of the common initial difference of the contact lens from the spectacle lens refraction. The subsequent refraction was not made under atropine which lessens probability of arrest.

In $\mathrm{R}$ (and $\mathrm{S}$, omitted) the refraction indicated by the row in the 'before treatment' side had no cycloplegia. Subsequent refractions were made under continuous atropine.

The refractions in the step graphs for Groups I, II, and III represent the spectacle refraction tested to the red side of the Duochrome test at $6 \mathrm{~m}$ without a cycloplegic. In Group IV the refractions were also done to the red side of Duochrome but with the contact lens in place and the power of any additional lenses required was added to or subtracted from the power of the contact lens. 


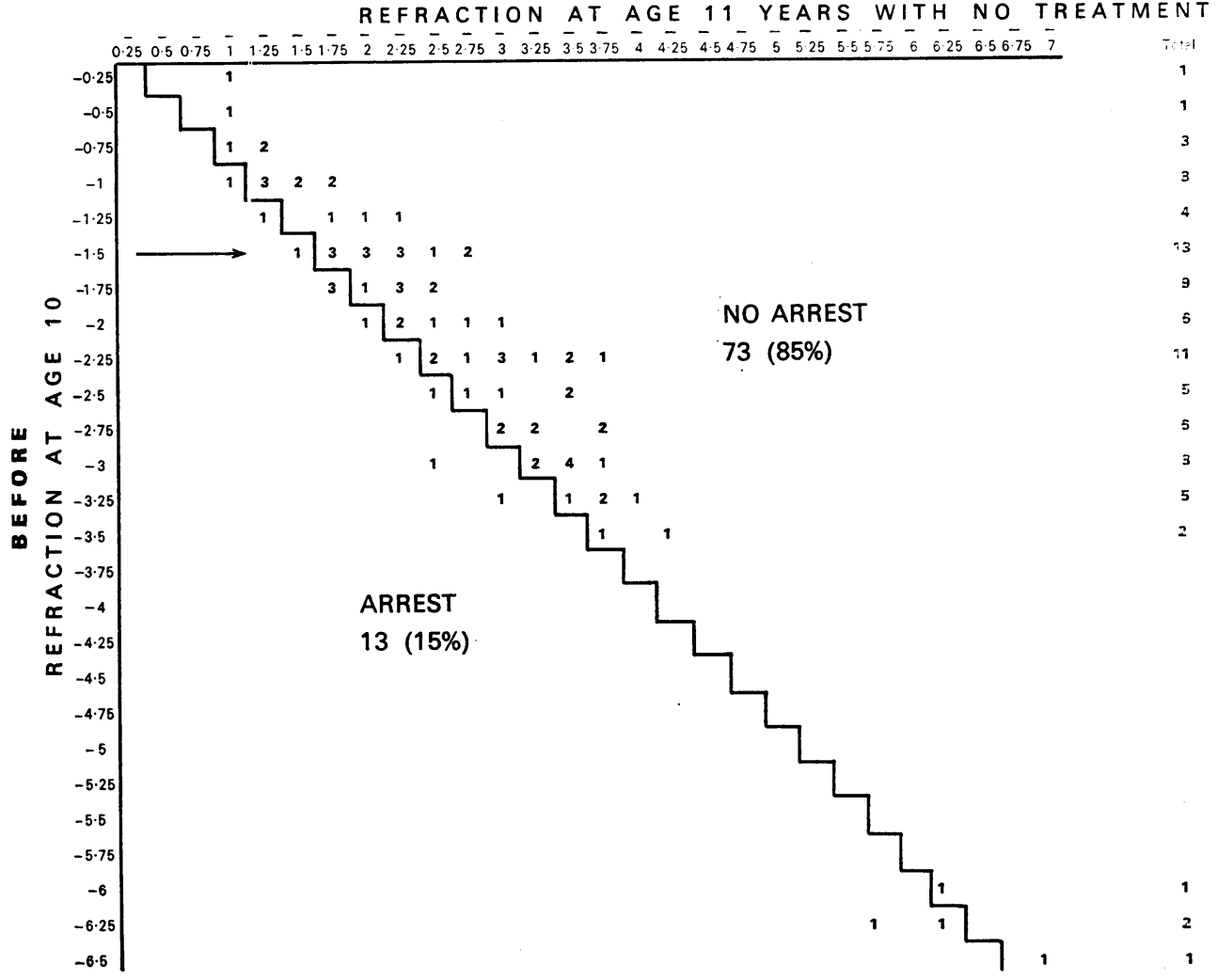

\section{GROUP I}

\section{Control group}

The control group showed that the myopia in many patients in the Bath area increased steadily at about 0.5 dioptre a year until somewhere between 18 and 23 years of age.

Two groups of graphs are shown as examples. Graphs $A$ and $C$ show the change in refraction for a group starting at 10 years of age. Graph A shows the change after I year and that 85 per cent of the eyes have not arrested. Graph B (omitted) shows the change after 2 years, when 93 per cent of eyes had become more myopic. Graph $\mathrm{C}$ shows the change after 4 years when in all the eyes the myopia has increased (there are no observations below the steps).

Graphs D, E, F (omitted) are similar and show the change in refraction for a group starting at 13 years of age. Graph $D$ shows the change in I year, $E$ after 2 years, and $F$ after 4 years, when all had increased.

Table I summarizes our findings showing the percentage of arrests and the mean increases in refraction per year.
Other graphs, not step graphs, also omitted, show that there was little difference between the sexes, and that there was still a steady increase at the age of 18 , suggesting that many eyes would not arrest completely until after the age of 20 years. The lack of growth-spurts and the late progression of myopia were not anticipated.

\section{GROUP II}

Treatment 2 Atropine, bifocals, and phenylephrine Children were divided into those who were II years or under and those who were 12 years or older at the beginning of treatment. Graphs $\mathrm{H}$ and J show the results of treatment after $I$ year and 2 years respectively, for those under 12 . Graphs L and $\mathrm{N}$ show equivalent results for the 12 years-andover group. The results show that refractions become less myopic by an average of $0.5 \mathrm{D}$ at the end of 3 months, and that treatment with a combination of bifocals and phenylephrine arrests the myopia, often for a considerable period. For example, Graph $\mathbf{N}$ shows that, even after 2 years, two-thirds of the 12-and-over age group had shown no increase in myopia. 
Group I-(no treatment)

Graph C

REFRACTION AT AGE 14 YEARS WITH NO TREATMENT

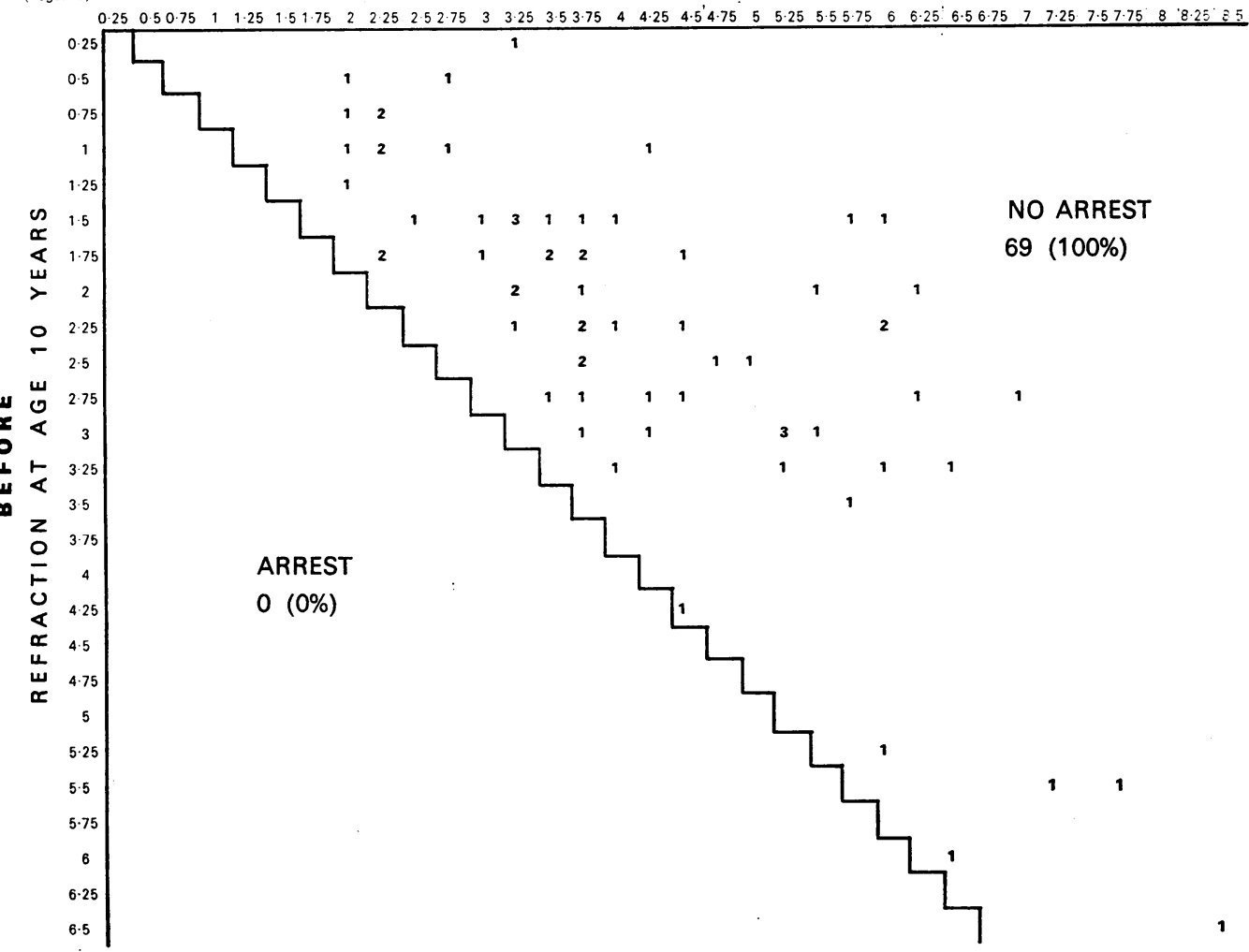

Table I Summary of results for control group

(a)

\begin{tabular}{|c|c|c|c|c|c|c|c|c|}
\hline \multirow{7}{*}{$\begin{array}{l}\text { Frequency } \\
\text { and percentage } \\
\text { of arrests }\end{array}$} & Starting at age & Graph & Age & Arrest & Percentage & No arrest & Percentage & size \\
\hline & Io years & A & II & 13 & 15 & 73 & 85 & 86 \\
\hline & & B & 12 & 5 & 7 & 71 & 93 & 76 \\
\hline & & C & 14 & $\circ$ & $\circ$ & 69 & 100 & 69 \\
\hline & 13 years & D & 14 & 7 & 14 & $4 \mathrm{I}$ & 86 & 48 \\
\hline & & $\mathrm{E}$ & 15 & $\mathbf{I}$ & 2 & 55 & 98 & 56 \\
\hline & & $\mathrm{F}$ & 17 & $\circ$ & $\circ$ & 46 & 100 & 46 \\
\hline
\end{tabular}

(b)

Average

increase
Year

First

Second

Third and fourth
Starting at age

\begin{tabular}{lll}
\hline ro years & & 13 years \\
$+0.49 \mathrm{D}$ & $+0.54 \mathrm{D}$ \\
$+0.57 \mathrm{D}$ & $+0.50 \mathrm{D}$ \\
$+0.45 \mathrm{D}$ & $+0.24 \mathrm{D}$
\end{tabular}




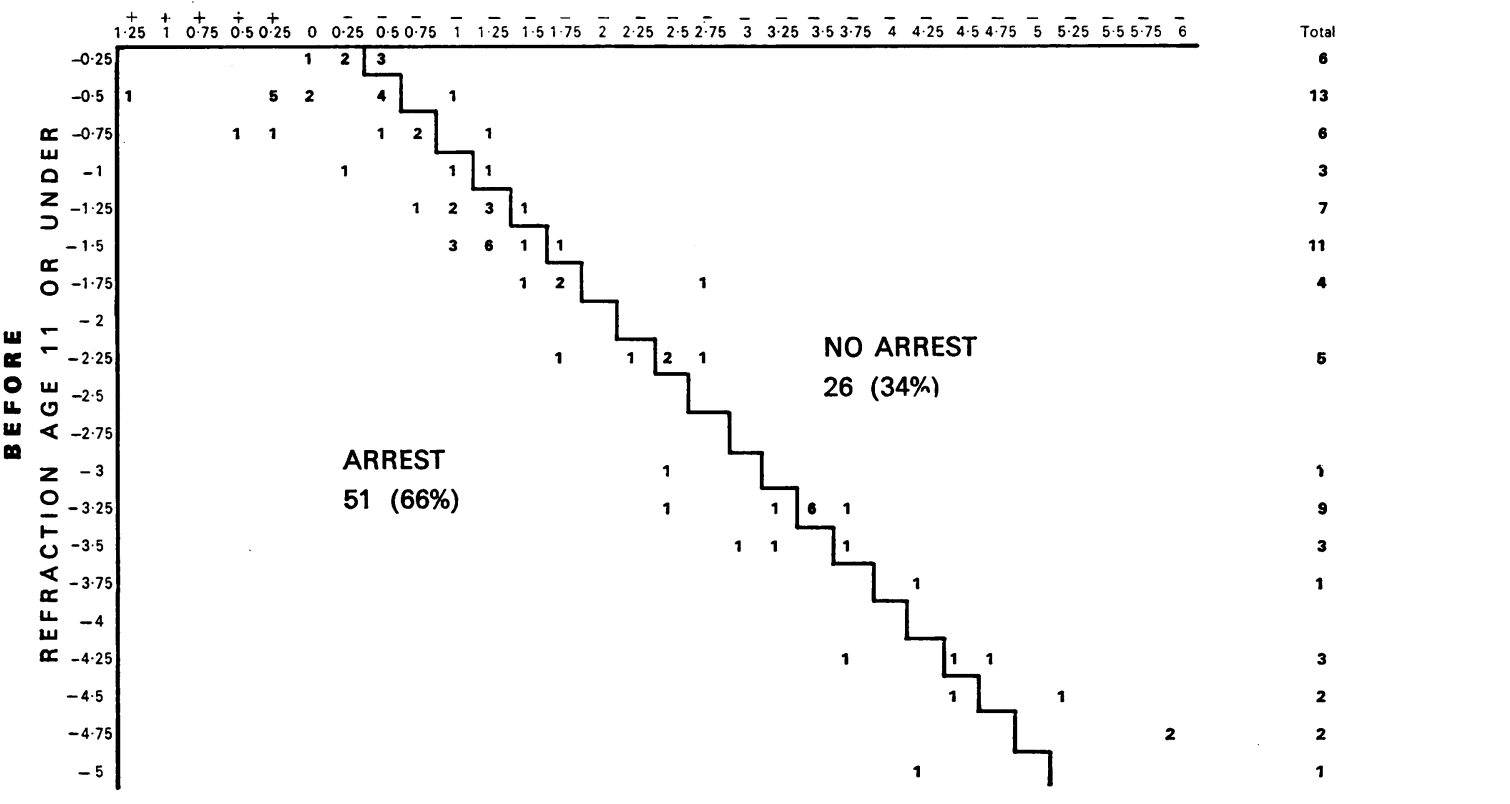

Table II summarizes the results for Group II. The percentage of arrests is much higher than for the control group, particularly for the 12-and-over group.

\section{GROUP III}

\section{Treatment 3 Contact lenses with no previous treatment}

Graphs $\mathrm{O}$ and $\mathrm{P}$ show the effect of wearing contact lenses for $I$ and 4 years respectively without any previous treatment, as was started in this series in 1960. The lenses were not less than $8.5 \mathrm{~mm}$ in diameter and, by being changed when needed, always had an apex clear pool. The first lenses were tri-curve, then Ruben off-set lenses were used as soon as they were available because they were easier to fit.

Over 4 years, the arrest rate was $3^{8}$ per cent. Subsequent figures showed that the arrest rate stayed between 20 and 30 per cent for as long as I3 years. Comparison with the control group again shows that this method arrests myopia in some cases although one or two eyes have worsened considerably as in the control group.

All patients had occasional 3-week gaps when the contact lenses were removed to see if there was any increase in the trial lens refraction. At first these periods were due simply to childish illnesses or a preference to do without the lenses for examinations, holidays, etc. But when Rengstorff (r969) published his work, the importance of the

Table II Summary of results for Group II. Frequency and percentage of arrests

\begin{tabular}{|c|c|c|c|c|c|c|c|}
\hline Age & Graph & Period (months) & Arrest & Percentage & No arrest & Percentage & $\begin{array}{l}\text { Sample } \\
\text { size }\end{array}$ \\
\hline $\begin{array}{l}\text { Up to } \\
\text { I I years }\end{array}$ & $\begin{array}{l}\text { G } \\
\text { H } \\
\text { I } \\
\text { J }\end{array}$ & $\begin{array}{r}\text { After } 6 \\
12 \\
18 \\
24\end{array}$ & $\begin{array}{l}71 \\
51 \\
25 \\
16\end{array}$ & $\begin{array}{l}80 \\
66 \\
48 \\
45\end{array}$ & $\begin{array}{l}18 \\
26 \\
28 \\
19\end{array}$ & $\begin{array}{l}20 \\
34 \\
52 \\
55\end{array}$ & $\begin{array}{l}89 \\
77 \\
53 \\
35\end{array}$ \\
\hline $\begin{array}{l}12 \text { years } \\
\text { and over }\end{array}$ & $\begin{array}{l}\mathrm{K} \\
\mathrm{L} \\
\mathrm{M} \\
\mathrm{N}\end{array}$ & $\begin{array}{r}\text { After } 6 \\
12 \\
18 \\
24\end{array}$ & $\begin{array}{l}61 \\
52 \\
39 \\
26\end{array}$ & $\begin{array}{l}86 \\
76 \\
64 \\
67\end{array}$ & $\begin{array}{l}10 \\
17 \\
22 \\
13\end{array}$ & $\begin{array}{l}14 \\
24 \\
36 \\
33\end{array}$ & $\begin{array}{l}71 \\
69 \\
61 \\
39\end{array}$ \\
\hline
\end{tabular}




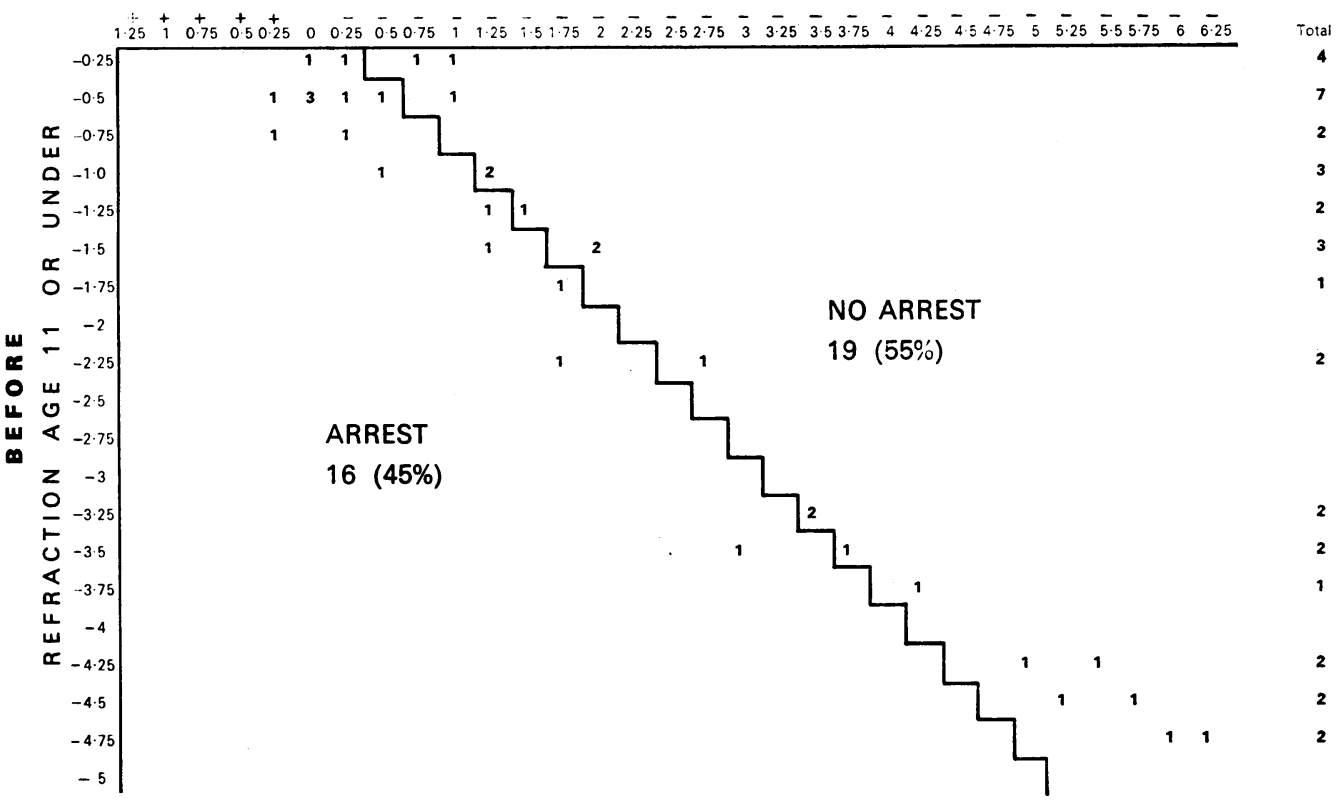

REFRACTION AFTER 1 YEAR

Graph L

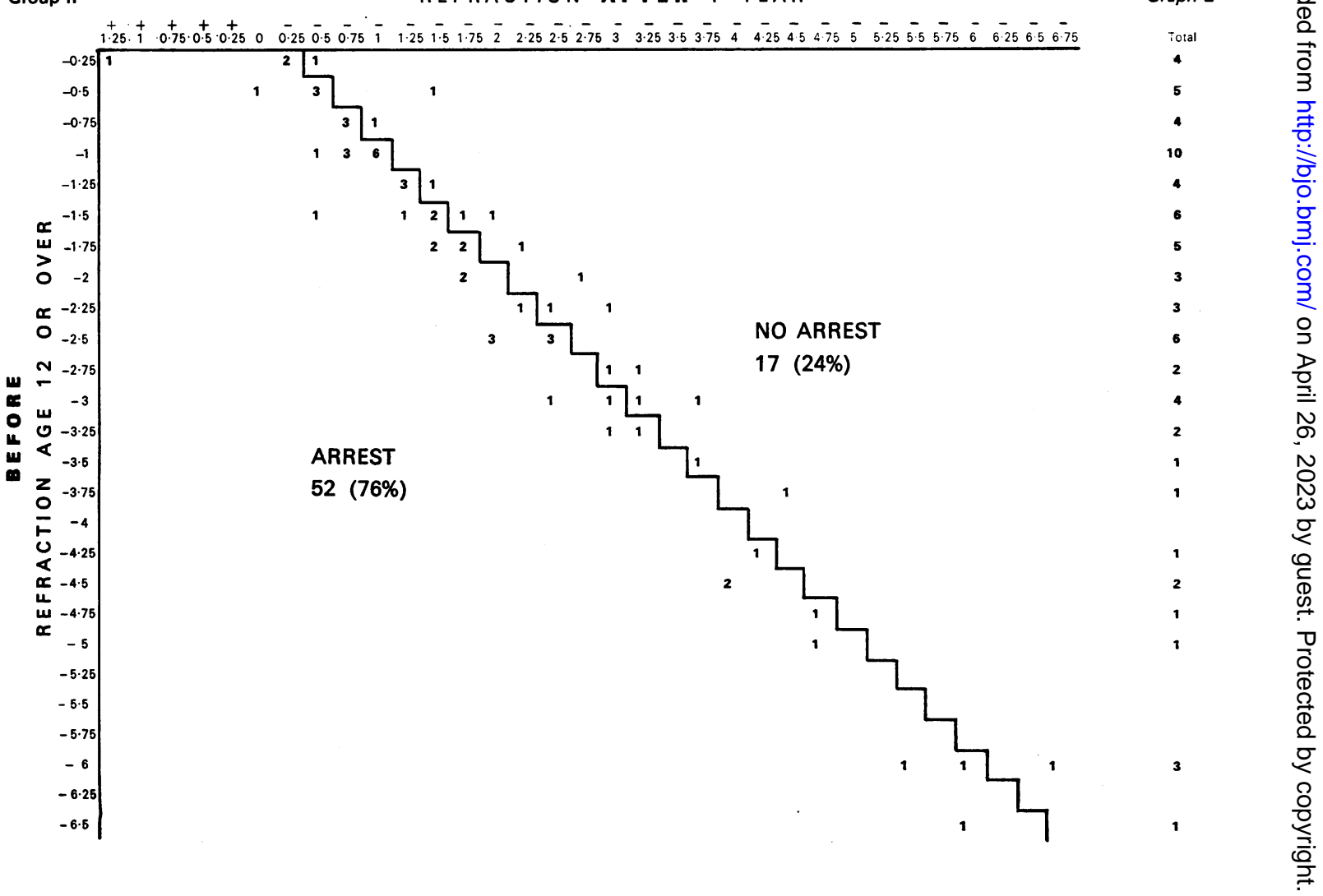




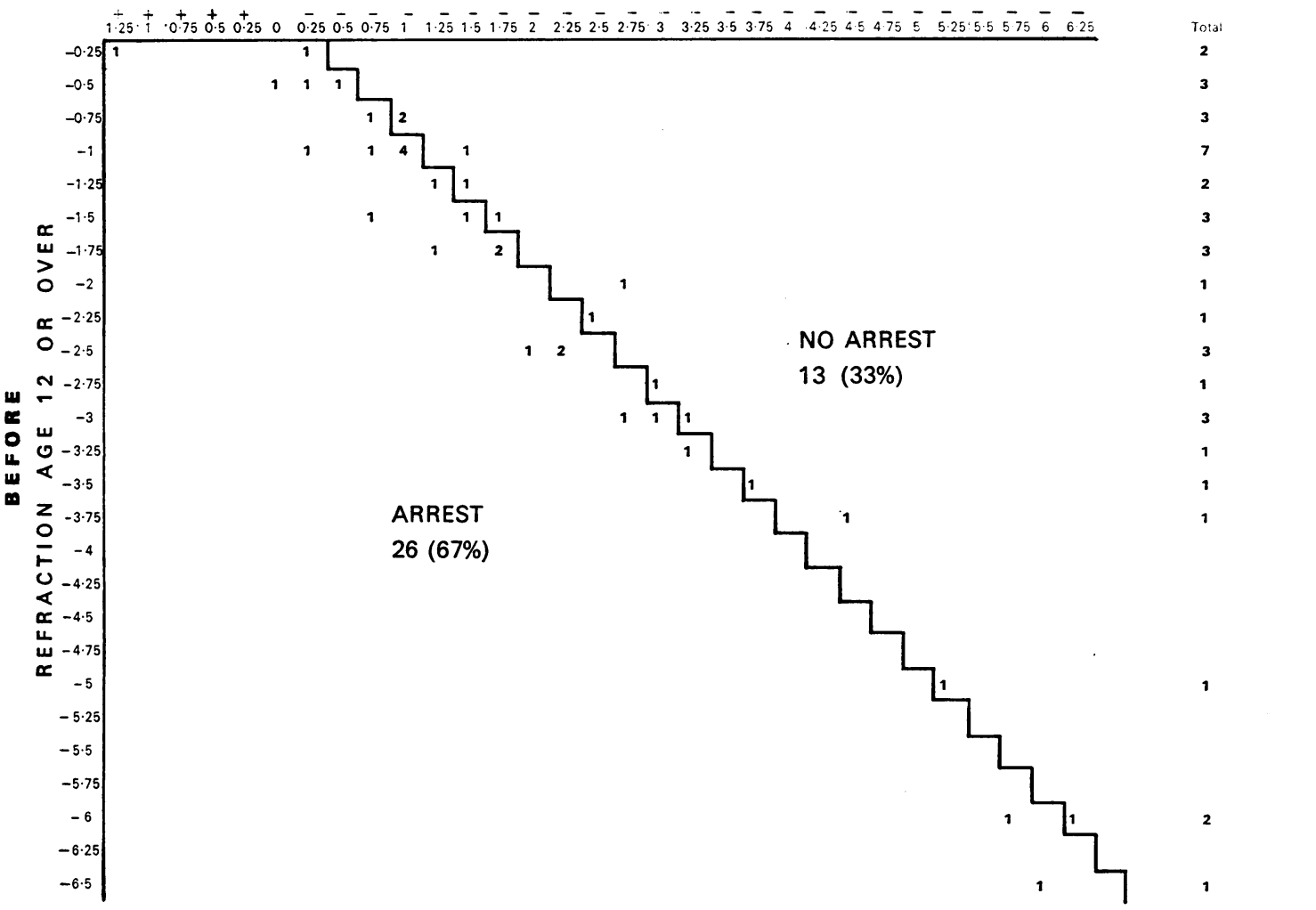

period of 3 weeks or longer after withdrawal of the contact lens to allow the cornea to regain its normal state became apparent.

\section{GROUP IV}

\section{Treatment 4 Contact lenses after previous treatment}

Graph $Q$ shows the effect of wearing contact lenses after atropine refraction, bifocals (plano/ $+\mathbf{I}_{5} \mathrm{D}$ ), and phenylephrine with continuation of bifocals (as plano/ $+\mathrm{r} \cdot 5 \mathrm{D}$ ) and the phenylephrine. After 6 to 9 months, two-thirds of the sample were arrested. These results are particularly promising because all the eyes had been previous failures in Group II. The sample size was fairly small because bifocals or phenylephrine were often forgotten when treatment was given at general clinics and, therefore, such cases have been excluded.

These patients also had 3-week gaps when the contact lenses were removed to see if there had been any increases in myopia, but they also had the addition of atropine I per cent three times a day during the third week. In this way the Rengstorff period of 3 weeks without the contact lens allows the cornea to regain its shape if there has been any change, and the atropine three times daily for a week fully paralyses the ciliary muscle. This paralysis thus matches the spectacle refraction at the full paralysis arranged when the contact lens was fitted originally and given its initial refraction. In this way the spectacle refraction and contact lens refraction complement each other.

GROUP V

\section{Treatment 5 Continuous atropine only}

Graphs $R$ and $S$ show the powerful action of atropine I per cent given once or twice a day to Caucasians for short periods. Graph $R$ showed the action after 3 months and $S$ (omitted) after 6 months.

Atropine has been used in two cases for over a year with similar results.

\section{Discussion}

The construction of the 19 step graphs from clinical records required a large amount of work and they require some explanation. The few patients who started with a very high $D$-value were excluded as their behaviour was not typical. A 


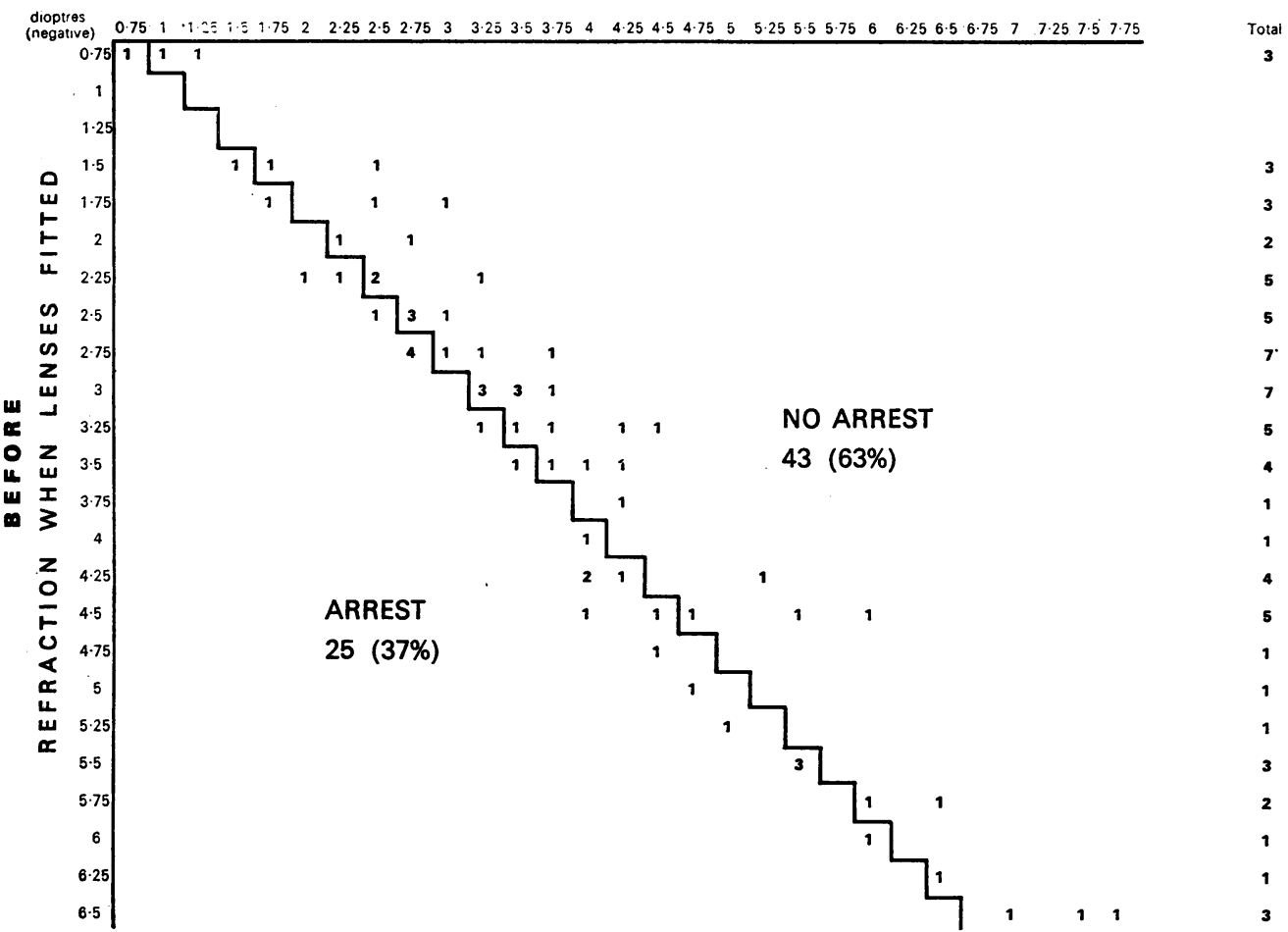

Group III

REFRACTION AFTER 4 YEARS

Graph P

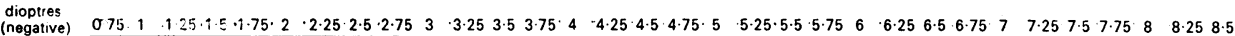

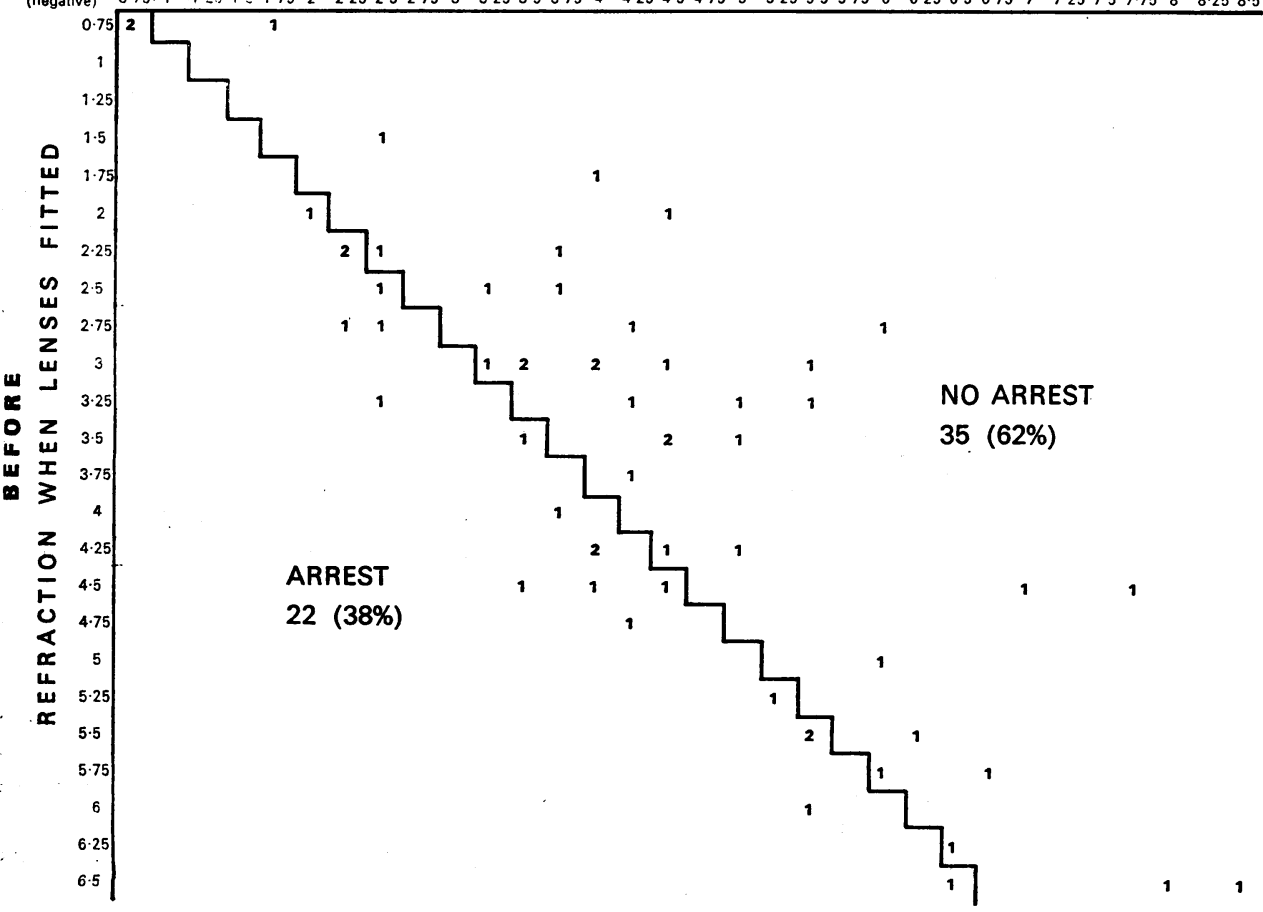



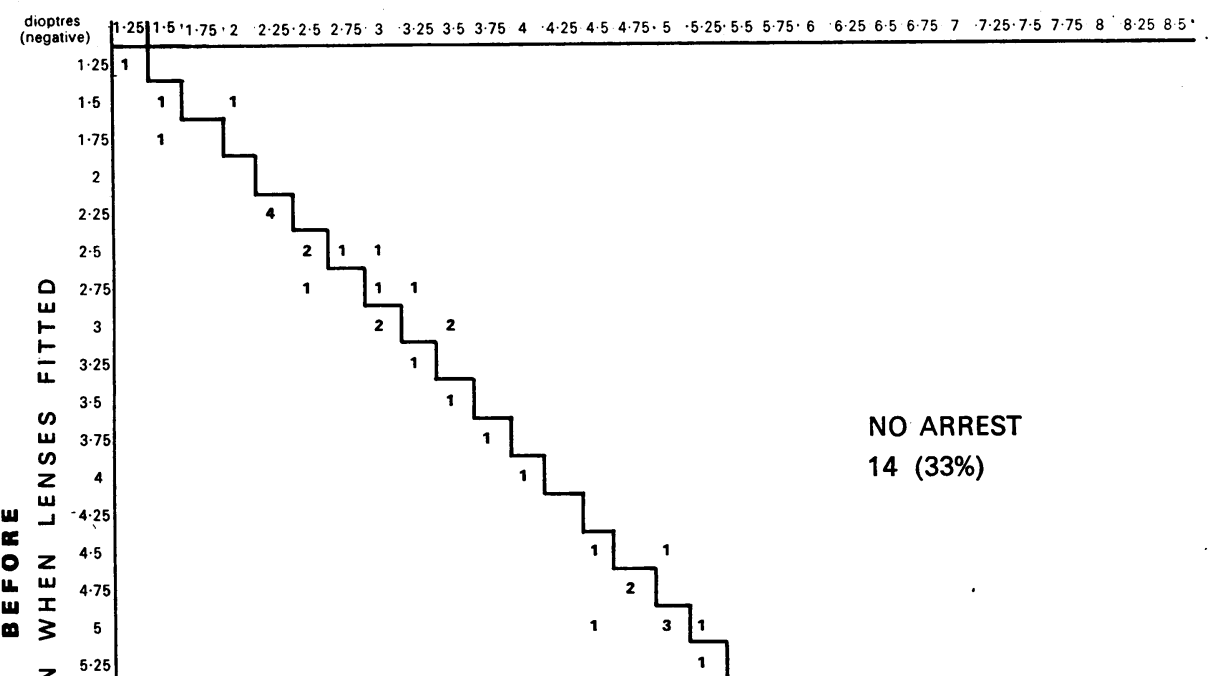

few other patients were excluded because their records were incomplete or otherwise unusable. Difficulties also arose because examinations were not carried out at exactly regular intervals. The procedure adopted was as follows. Graph A shows the changes 'over I year' for the control group ro-year-olds. In fact this graph includes all eyes which were examined at the age of ro years and then again between 9 and 15 months later (that is, I year \pm 3 months). Similar rules were used for the other graphs. Thus not all eyes are included in every graph. In addition patients who were over I 5 years old at the start of treatment were excluded.

Table III summarizes the results of this investigation. Inspection of the Tables and Graphs shows quite clearly that the observed percentages of arrests are much higher in the treatment groups than in the control group. Similarly the mean change in refraction is lower for the treatment groups than for the control group. Although the samples are not 'random' in the sense used by statisticians, the control group and the sample for Method 2 were selected in an unsystematic way and we would expect the observed statistics to be a guide to the behaviour of the population as a whole.

We shall not give the results of significance tests for two reasons. First because the samples are not strictly random and secondly because the differences are of such a large order of magnitude that a test is quite unnecessary. Now that significance tests have become so fashionable, it seems to have been forgotten that significance tests are useful when the results are not clear-cut. (We can assure the reader that the results are 'statistically significant'.)

Comparison of Groups I and II may at first sight suggest that the two groups differ too much in their characteristics to be compared. The reader may also find it surprising that some eyes in Group II are less myopic after treatment. But it is important to realize that one must compare percentages before treatment to see if the groups are reasonably comparable. For example, for the control groups over I year Graphs A and D (omitted) there are 


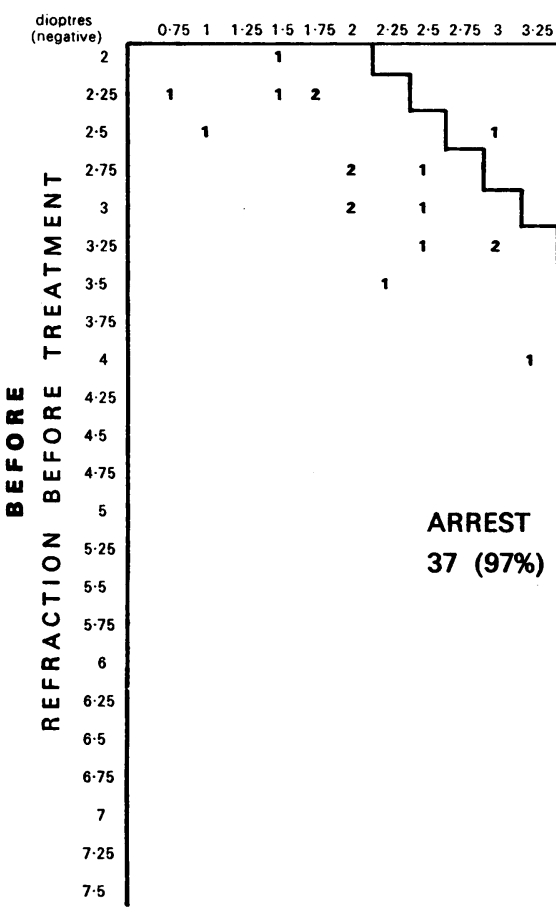

Table III Summary of results

(a) Percentage of arrests

\begin{tabular}{|c|c|}
\hline Group & $\begin{array}{l}\text { After I yr } \\
\text { (percentage) }\end{array}$ \\
\hline \multirow{3}{*}{$\begin{array}{l}\text { I } \\
\text { II } \\
\text { III }\end{array}$} & $\begin{array}{l}15 \\
66\end{array}$ \\
\hline & 37 \\
\hline & After 6-9 mths \\
\hline \multirow[t]{2}{*}{ IV } & 67 \\
\hline & After 6 mths \\
\hline V & 97 \\
\hline
\end{tabular}

(b) Average change in myopia (in dioptres)

\begin{tabular}{|c|c|}
\hline Group & After I $y r$ \\
\hline \multirow[t]{2}{*}{$\begin{array}{l}\text { I } \\
\text { II } \\
\text { III }\end{array}$} & $\begin{array}{l}0.52 \text { (increase) } \\
0.04 \text { (decrease) } \\
0.35 \text { (increase) }\end{array}$ \\
\hline & After 6-9 mths \\
\hline IV & 0.24 (increase) \\
\hline $\mathbf{V}$ & $\begin{array}{l}\text { After } 6 \text { mths } \\
0.58 \text { (decrease) }\end{array}$ \\
\hline
\end{tabular}


about 50 per cent. Apart from those leaving the area or giving up treatment for some other reason such as illness, about one-quarter of the original sample was transferred to contact lenses and the remaining quarter thought their myopia had been permanently arrested and so stopped the treatment. Some of these reappeared years later when the myopia had again increased. Others felt that they did not want to continue with the phenylephrine whether the myopia was increasing or not.

In Group III, 20 per cent dropped out; of these eight were failures, and one left the area. Of the successes one left the area. Of the children who tried contact lenses 15 per cent were unable to continue but are not included in the Group III graph.

The long delay in some before the increase in myopia resumed gives rise to the clinical observation that the earlier treatment is started, the more likely is a subsequent increase to be prevented.

\section{Conclusions}

This empirical treatment was started in 1960 with the idea of preventing retinal detachment. In view of the disappointing history of the treatment of myopia, little, if any, arrest was expected, but these results suggest that myopia can be arrested in 50 per cent of cases at the stage at which they present in a Caucasian population.

Even in the cases in which arrest has not been achieved, with the exception of Group III, the increase in myopia has been less than in the control group. This means that many have been partially arrested.

The least successful results were obtained in Group III who were treated with contact lenses only without the addition of atropine (Method 3). Although Otsuka (1967) gave up the use of atropine in Japan, its use seems to be of profound significance in Caucasians, a conclusion which is supported by the results of Bedrossian (1967) and Gimbel (1973).

This assessment was undertaken to see what the clinical effects of the various methods of treatment given from 1960 had been. Discussion of the causes of arrest will be the subject of future papers.

T. Stuart-Black Kelly would like to thank Mr Donald Butler for his help with the contact lenses and refractions and Professor E. S. Perkins for his help and encouragement since 1959 .

The cost of the assessment was provided by the Bath Area Medical Research Trust and of various instruments by the South Western Regional Board.

\section{References}

BEDRossian, R. H. (1967) 'Proceedings of the XX International Congress of Ophthalmology, Munich, 1966'. Excerpta Medica, Amsterdam GIMBEL, H. v. (1973) Canad. F. Ophthal., 8, 527

OTSUKA, J. (1967) Acta Soc. ophthal. jap. (Tokyo), 7, 24

RENGSTORFF, R. H. (1969) Amer. F. Optom., 46, 357 